SYMPOSIUM

\title{
Role of lung function testing in the management of mechanically ventilated infants
}

\section{A Schibler, U Frey}

Arch Dis Child Fetal Neonatal Ed 2002;87:F7-F10

The mechanical characteristics of the ventilated lung can only be interpreted when the volume of the lung, the elastic properties, and the degree of airway obstruction have been accurately quantified by pulmonary function testing. More gentle ventilation strategies (permissive hypercapnia) are used, and the efficacy of mechanical ventilation can be verified in the intensive care unit. Pulmonary function testing brings new insights, awareness, and applications, but its limitations need to be taken into account when interpreting the acquired data.

See end of article for authors' affiliations ...................

Correspondence to: Dr Schibler, Neonatal and Paediatric Intensive Care Unit, Department of Paediatrics, Children's Hospital University of Bern, 3010 Bern, Switzerland; andreas.schibler@insel.ch
M any advances have been made in pulmonary function testing during mechanical ventilation in infants and the techniques and equipment necessary are readily available for bedside ventilatory measurements. The complex interrelationship of lung volume, airway resistance, and lung tissue characteristics is summarised by the term viscoelastic properties of the lung. Currently, there is no "optimal" pulmonary function test (PFT) for bedside monitoring. Such a PFT would consist of a single minimally invasive procedure that would produce accurate data, and the technology should be sensitive enough to measure absolute values and detect important changes in variables being measured. Most of the sophisticated measurement techniques available are for research purposes; they are not clinically applicable and do not directly improve the care of the ventilated patient. This review explores the measurement techniques in ventilated infants and the routine use of PFT. Oxygen therapy and its monitoring are discussed in the article in this series by Kotecha and Allen.

\begin{abstract}
"Most of the sophisticated measurement techniques available are for research purposes; they are not clinically applicable and do not directly improve the care of the ventilated patient."
\end{abstract}

Before any PFT measurement, we need to know: $(a)$ the clinical question; $(b)$ how we can quantify the degree of a respiratory disorder; $(c)$ how we can show the physiological effect of an intervention such as the administration of a bronchodilator or change in ventilation mode; $(d)$ how we can monitor the evolution of lung disease; $(f)$ whether we can predict outcome. In general there are three major groups of respira- tory disorders requiring mechanical ventilation in the newborn infant:

(1) respiratory distress syndrome (RDS) of the preterm infant with surfactant deficiency, which may progress to chronic lung disease (CLD);

(2) the structurally abnormal lung as seen in infants with congenital diaphragmatic hernia and hypoplastic lungs;

(3) acquired respiratory disease such as lung infection or meconium aspiration syndrome.

The changes in lung compliance and lung volume that occur after the administration of surfactant to infants with RDS have been described elsewhere. ${ }^{12}$ Several authors have attempted to predict the development of CLD following RDS using PFT measurements during mechanical ventilation. ${ }^{3}$ Expiratory resistance is increased in respiratory infections in which administration of aerosolised bronchodilators has been investigated. Only a few studies have shown a beneficial effect. ${ }^{4}$ However, it seems reasonable to administer a bronchodilator on a trial basis to individual patients with airway obstruction and measure the clinical response with PFT. These are some examples of successfully applied PFT in research. But can lung function testing be used clinically? For detailed technical descriptions of equipment and measurement procedures, we refer the reader to standard lung physiology textbooks. ${ }^{5}$

Some important concepts of infant lung physiology and lung function testing need to be discussed before we can use any specific test. Lung mechanics do not follow linear rules; the relation between airways and the tissue is known as the mechanical interdependence. As the lungs are inflated during mechanical ventilation, the airways distend because of their attachment to the collagen matrix of the lungs. Thus airway resistance decreases as the volume increases. In contrast, during mechanical ventilation, the resistance imposed by the tissues of the lungs and chest wall increases progressively during inspiration. Furthermore, the respiratory system exhibits frequency dependent behaviour. Improvement or deterioration in the clinical condition of a ventilated infant usually leads to adjustment of the

Abbreviations: PFT, pulmonary function test; RDS, respiratory distress syndrome; CLD, chronic lung disease; $E T$, endotracheal tube; PEEP, positive end expiratory pressure; $\mathrm{PTCCO}_{2}$, transcutaneous carbon dioxide tension; $\mathrm{PETCO}_{2}$, end tidal carbon dioxide tension; $\mathrm{C}_{\text {dyn }}$ dynamic compliance; $R_{e}$, dynamic resistance; FRC, functional residual capacity 

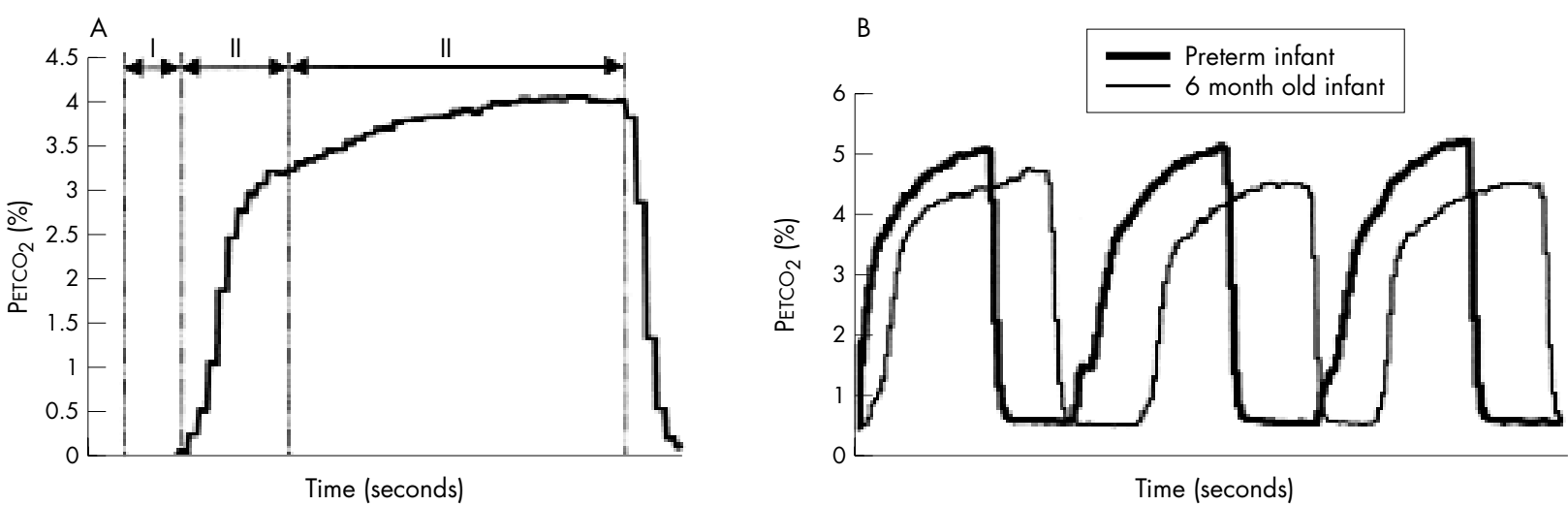

Figure 1 (A) The $\mathrm{CO}_{2}$ waveform has three phases. PETCO 2 remains zero as gas from the anatomic dead space leaves the airway (phase I); it then rises sharply as alveolar gas mixes with dead space gas (phase II); as purely alveolar gas is exhaled, the curve levels (phase III). (B) The $\mathrm{CO}_{2}$ waveform from a small preterm infant (bold line) without an alveolar plateau (phase III), compared with that in a 6 month old infant (thin line) where the phase III is present.

ventilator settings. Such adjustments can mask the changes in lung mechanics, which are due to the underlying disease process. The presence of an endotracheal tube (ETT) further complicates the measurement of PFT. For instance, the size and length of the ETT add significantly to the overall airway resistance. Lung volumes measured through an ETT may be greater than during spontaneous breathing because of the airflow limitation during expiration leading to incomplete emptying and hence to intrinsic positive end expiratory pressure (PEEP). Leaks around the ETT also complicate measurements of respiratory mechanics. Applying gentle cricoid pressure usually abolishes small leaks.

\section{TRANSCUTANEOUS $\left(\mathrm{PtCCO}_{2}\right)$ and end tidal $\left(\mathrm{PeTCO}_{2}\right)$ $\mathrm{CO}_{2}$ monitoring}

Infants with RDS and developing CLD are quite often managed on a ventilator for several weeks. For optimal ventilatory management in the infant, blood gas analysis is the ideal but because of obvious restrictions ( sample size for blood gas tensions), non-invasive measurement of $\mathrm{PCO}_{2}$ is useful in neonatal intensive care units. Changes in $\mathrm{PCO}_{2}$ are almost always due to alterations in alveolar ventilation. $\mathrm{PTCCO}_{2}$ gives a good estimate of the true arterial $\mathrm{PCO}_{2}$ if skin perfusion is satisfactory. However, $\mathrm{PTCCO}_{2}$ is limited only to monitoring and provides no direct information on lung function. $\mathrm{PeTCO}_{2}$ is best measured by inline infrared spectroscopy and can be used to evaluate respiratory pattern, ventilatory dead space, ETT placement, and mechanical ventilator failures. The dead space of the connectors must be reduced to less than $1 \mathrm{ml}$. An increase in $\mathrm{PETCO}_{2}$ is usually associated with hypoventilation in relation to $\mathrm{CO}_{2}$ production, but may rarely be caused by a sudden change in cardiac output. ${ }^{6}$ A decrease in $\mathrm{PeTCO}_{2}$ may reflect an improvement in ventilation distribution, sudden pulmonary hypoperfusion, or an obstruction or disconnection of the ETT/ventilator. When the $\mathrm{PETCO}_{2}$ is displayed against time (capnogram), the shape of the curve provides important information on physiological dead space. However, there are major limitations to $\mathrm{PETCO}_{2}$ : it deviates significantly from $\mathrm{PaCO}_{2}$ in patients with severe pulmonary impairment and ventilation/perfusion mismatching or shunt. ${ }^{7}$ This can be estimated by measurement of the alveolar-arterial oxygen gradient. The $\mathrm{PaO}_{2} / \mathrm{PAO}_{2}$ ratio can be calculated at the bedside, with the formula

$$
\mathrm{PAO}_{2}=\left(\mathrm{PBARO}-\mathrm{PH}_{2} \mathrm{O}\right) \times\left(\mathrm{FIO}_{2}-\mathrm{PaO}_{2}\right)
$$

which can be simplified to: $713 \times \mathrm{FIO}_{2}-\mathrm{PaO}_{2}$. $\mathrm{PeTCO}_{2}$ is a direct estimate of $\mathrm{PaCO}_{2}\left(\mathrm{PeTCO}_{2}=\mathrm{PaCO}_{2} \pm 3.4 \mathrm{~mm} \mathrm{Hg}\right)$ if the ratio between $\mathrm{PaO}_{2}$ and $\mathrm{PAO}_{2}$ is greater than 0.3.
A further specific feature of the $\mathrm{PeTCO}_{2}$ signal in infants is the distinct shape of the $\mathrm{CO}_{2}$ waveform (fig l). The $\mathrm{CO}_{2}$ waveform has three phases (fig $\mathrm{lA}$ ). $\mathrm{CO}_{2}$ waveforms from a preterm infant and from a 6 month old infant are shown in fig $1 \mathrm{~B}$. The shallow upward sloping of phase III and the absence of a plateau in the preterm infant compared with the older infant are attributed to the longitudinal gas concentration gradients within the airway and to the interaction between gas convection and molecular diffusion, airway geometry, and diffusion of gas from blood. Age related changes in the slope of phase III may reflect growth of the alveolar airway cross section. The respiratory dead space is remarkably constant over age in ventilated healthy children, with a ratio of dead space to tidal volume of $0.25-0.29 .{ }^{8}$ The effective dead space of a ventilated infant is about $1-2 \mathrm{ml} / \mathrm{kg}$, and the tidal volume $5-8 \mathrm{ml} / \mathrm{kg}$.

What are the conclusions for bedside management? Permissive hypercapnia is a strategy for the management of patients receiving assisted ventilation in which relatively high levels of $\mathrm{PCO}_{2}\left(\mathrm{PaO}_{2}<7.5 \mathrm{kPa}\right.$ and $\left.\mathrm{pH}>7.2\right)$ are accepted to avoid high tidal volumes, and pulmonary overdistension to decrease lung injury. ${ }^{9}$ Only $\mathrm{PTCCO}_{2}$ qualifies for $\mathrm{PaCO}_{2}$ monitoring in such circumstances because infants being treated with permissive hypercapnia are likely to have a low $\mathrm{PaO}_{2} / \mathrm{PAO}_{2}$ ratio.

\section{MEASUREMENT OF TIDAL VOLUME, DYNAMIC COMPLIANCE, AND RESISTANCE}

During the acute phase of a lung disease and treatment with surfactant lung volumes for example, compliance and resistance change rapidly, which may lead to overdistension of some parts of the lung and may be the cause of ventilator induced pneumothorax. It is important to monitor such rapid changes in the viscoelastic properties of the lung. Most sophisticated ventilators equipped with accurate flow meters measure tidal volumes. Ventilation strategy in neonatology is mainly based on the prevention of barotrauma (inspiratory pressure limitation). A different approach is the prevention of volutrauma (excessive inspiratory lung volume). The volume versus pressure issue is a semantic one, because transpulmonary pressure determines alveolar volume. A more scientific approach is to describe the relation between distending pressure and volume. Dynamic compliance $\left(\mathrm{C}_{\mathrm{dyn}}\right)$ of the lung is defined as the change of volume per unit change in pressure measured during mechanical ventilation. Dynamic resistance $\left(R_{e}\right)$ is calculated accordingly with the pressure change per flow. Static compliance and resistance of the lung can be obtained by very slow inflation of the lung, a procedure that is not feasible in the sick patient. $\mathrm{R}_{\mathrm{e}}$ and $\mathrm{C}_{\mathrm{dyn}}$ are best determined by multiple linear regression analysis of the breath by breath pressure, flow, and volume signal using a least squares fit of 


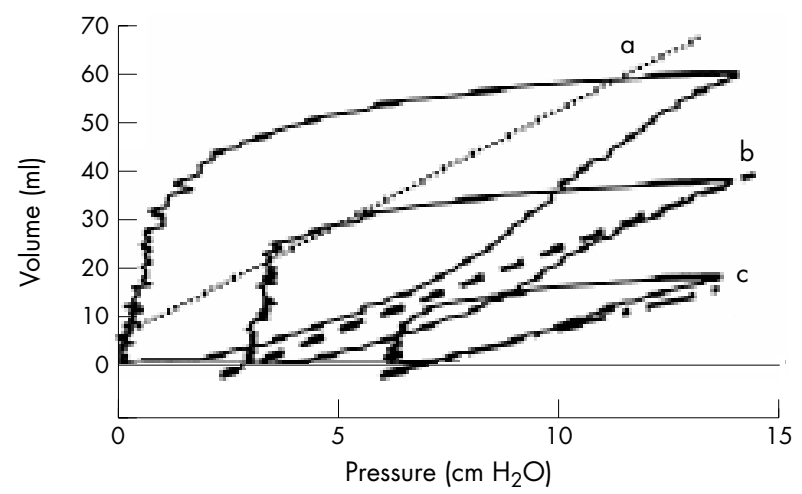

Figure 2 Three different pressure-volume curves of an infant (3.2 $\mathrm{kg})$ with normal lungs during mechanical ventilation are shown. Positive end expiratory pressure has been changed from 0 (curve a) to 3 (curve b) and to $6 \mathrm{~cm} \mathrm{H}_{2} \mathrm{O}$ (curve c). $\mathrm{C}_{\text {dyn }}, \mathrm{R}_{\mathrm{e}}$, and functional residual capacity were: curve a, $4.4 \mathrm{ml} / \mathrm{cm} \mathrm{H}_{2} \mathrm{O}, 0.031 \mathrm{~cm}$ $\mathrm{H}_{2} \mathrm{O} / \mathrm{ml} / \mathrm{s}$, and $60 \mathrm{ml}$; curve b, $3.0 \mathrm{ml} / \mathrm{cm} \mathrm{H}_{2} \mathrm{O}, 0.025 \mathrm{~cm}$ $\mathrm{H}_{2} \mathrm{O} / \mathrm{ml} / \mathrm{s}$, and $81 \mathrm{ml}$; curve $\mathrm{c}, 2.0 \mathrm{ml} / \mathrm{cm} \mathrm{H}_{2} \mathrm{O}, 0.021 \mathrm{~cm}$ $\mathrm{H}_{2} \mathrm{O} / \mathrm{ml} / \mathrm{s}$, and $92 \mathrm{ml}$.

the equation of motion of the passive respiratory system. ${ }^{10}$ Newer types of ventilators provide a measurement of compliance and resistance, but most of them use the MeadWhittenberg technique, which assumes that $\mathrm{R}_{\mathrm{e}}$ and $\mathrm{C}_{\mathrm{dyn}}$ are constant throughout inspiration and expiration and bases its estimates of mechanics on only two points within the respiratory cycle. It must be emphasised that compliance is a function not only of the elastic properties of the lung but also of its volume. Therefore, its value varies with different volumes depending on the shape of the pressure-volume (PV) curve and on alteration of mechanical ventilation settings, including respiratory frequency and inspiratory and end expiratory pressure. The measurement of $\mathrm{R}_{\mathrm{e}}$ and $\mathrm{C}_{\mathrm{dyn}}$ provides two pieces of important information: (a) the change in elastic properties of the lung-for example, after the application of surfactant; (b) it guides changes to the ventilator settings to avoid over-recruitment-that is, hyperinflation-of the lung with each ventilatory cycle if the patient is ventilated above the lower inflection point of the PV curve.

Figure 2 illustrates the effect on lung volume and lung mechanics of alterations in ventilator settings in a full term infant with normal lungs. The measured $\mathrm{C}_{\mathrm{dyn}}$ increased and $\mathrm{R}_{e}$ decreased as PEEP increased. This example illustrates that $\mathrm{C}_{\mathrm{dyn}}$ is dependent on lung volume and should ideally be corrected for functional residual capacity. If the ventilator pressure settings remain unaltered and a large increase in lung volume

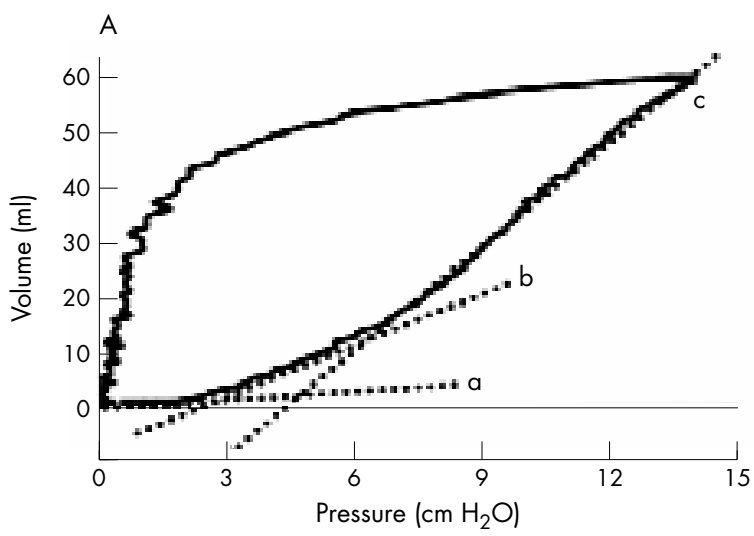

occurs after treatment, with surfactant for example, the infant may be overventilated, and dynamic compliance may remain low because of the influence of the stiff, overdistended lung units. Increased PEEP may improve lung recruitment so that the recruitment interval (lower inflection point) disappears (fig 3). Unfortunately, there are no published normal values for $\mathrm{C}_{\mathrm{dyn}}$ for healthy infants, but as a rule of thumb, the normal respiratory system compliance of an infant is about $1 \mathrm{ml} / \mathrm{cm}$ $\mathrm{H}_{2} \mathrm{O} / \mathrm{kg}$. The same care is required if resistance is measured during mechanical ventilation. Also, when a patient with some airway obstruction and hyperinflation is given a bronchodilator and subsequently decreases absolute lung volume, then improvements in airway calibre and therefore resistance resulting from treatment may be offset by an increase in resistance caused by the fall in lung volume.

Tidal volume, $\mathrm{R}_{\mathrm{e}^{\prime}}$ and $\mathrm{C}_{\mathrm{dyn}}$ are easily and quickly assessed in the intensive care unit. They provide useful information both for monitoring pulmonary function for ventilation strategies, such as permissive hypercapnia, and on the disease process, as long as their limitations are appreciated.

\section{FUNCTIONAL RESIDUAL CAPACITY (FRC)}

As discussed above, lung volume is an important variable, and, without its knowledge, lung mechanics such as $\mathrm{R}_{\mathrm{e}}$ and $\mathrm{C}_{\mathrm{dyn}}$ are difficult to interpret. The empirical application of PEEP in diseased lungs is usually based only on clinical judgment such as blood gas analysis, chest expansion on $x$ ray film, and pressure volume loops. Many studies ${ }^{11}$ have shown that, at higher levels of PEEP, FRC increases, areas of collapsed lung re-expand, and air trapping may be decreased. Higher PEEP levels may also change the mechanical properties of the already open lung units by increased distension and surfactant production as well as alteration of the time constant within these lung units. Pulmonary vascular resistance depends on FRC, and overdistension of the lung with increased PEEP may cause increased pulmonary vascular resistance and decreased cardiac output, resulting in decreased delivery of oxygen to peripheral tissues. The presence of severe collapse/consolidation may lead to overdistension of the relatively healthy parts of the lungs, if FRC is "normalised" with high PEEP. Currently, the volume at end expiratory level (FRC) is the only volume that can be accurately measured in infants during mechanical ventilation. FRC can be measured using a closed circuit helium (He) dilution technique, an open circuit nitrogen $\left(\mathrm{N}_{2}\right)$ technique, or sulphur hexafluoride $\left(\mathrm{SF}_{6}\right)$ washout. All three techniques can be used during both spontaneous breathing and mechanical ventilation. The helium dilution technique is not further described in this review because of its limited application at the bedside. The nitrogen washout technique is based on

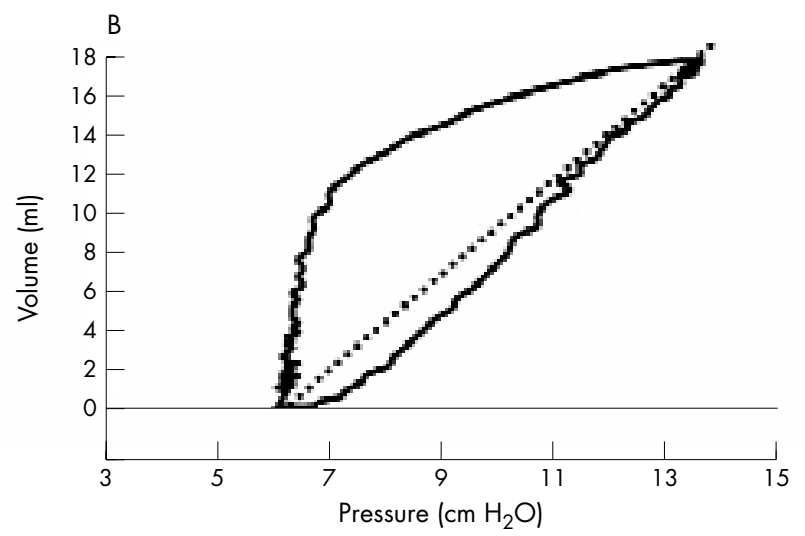

(A), a lower inflection point can be seen (crossing of line a and b). With increasing inspiratory pressure, the lungs are inflated and the pressure-volume relation becomes linear (line c). If PEEP is set to $6(B)$, most of the inspiratory limb of the pressure-volume curve is linear. 

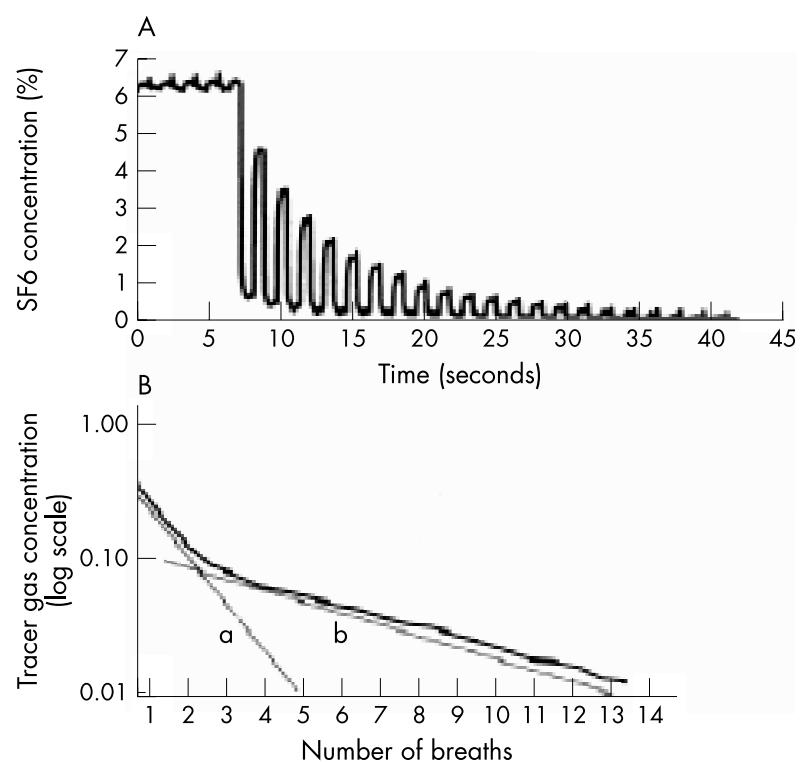

Figure 4 (A) $\mathrm{An} \mathrm{SF}_{6}$ washout using an ultrasonic flow meter. (B) $\mathrm{An}$ $\mathrm{SF}_{6}$ washout of an infant with severe ventilation inhomogeneity. The $\mathrm{SF}_{6}$ concentration (log scale) is plotted against the number of breaths. There is an initial fast lung compartment (line a) followed by a slow emptying one (line b).

washing out the $\mathrm{N}_{2}$ from the lungs by increasing the $\mathrm{FIO}_{2}$ to $\mathrm{l}$. If the amount of $\mathrm{N}_{2}$ washed out is measured and the initial alveolar $\mathrm{N}_{2}$ concentration is known, then the lung volume from which point the washout started can be calculated.

Recently newer techniques using $\mathrm{SF}_{6}$ as a tracer gas have been developed. ${ }^{12}{ }^{13} \mathrm{SF}_{6}$ is an inert gas, which is fed into the inspiratory limb of the ventilator circuit. The concentration of $\mathrm{SF}_{6}$ is measured breath by breath using an infrared analyser or an ultrasonic flow meter (fig 4). The expired $\mathrm{SF}_{6}$ volume is calculated by integrating $\mathrm{SF}_{6}$ flow (area under the curve), and FRC is obtained by dividing the expired $\mathrm{SF}_{6}$ volume by the end

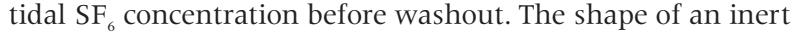
tracer gas washout provides important information on ventilation distribution (fig 4). In patients with lung disease, nonuniform ventilation results in a curved plot because different lung units have their tracer gas diluted at different rates. Thus, the well ventilated lung units cause a rapid fall in the tracer gas concentration whereas slowly ventilated air spaces are responsible for the long tail of the washout. There are numerous indices to describe such a washout curve, the most popular being the lung clearance index, the pulmonary clearance delay, and moment ratio analysis. A full description of these indices would exceed the intention of this review, but they are very useful for discrimination between normal and abnormal ventilation distribution. ${ }^{14-18}$

Which technique can be used for bedside ventilatory management? The $\mathrm{N}_{2}$ washout technique allows very accurate measurement of FRC but is limited to patients with $\mathrm{FIO}_{2}<0.65 .{ }^{19}$ The $\mathrm{N}_{2}$ washout technique needs bulky equipment (two ventilators and a mass spectrometer) and is therefore not for the routine bedside use. Newer equipment using $\mathrm{SF}_{6}$ is now commercially available. The same equipment can be used in spontaneously breathing infants to measure lung volume and ventilation distribution. Lung volumes are of interest in lung hypoplasia and when PEEP needs to be adjusted in infants with lung disease. The measured FRC in spontaneously breathing healthy infants and children is in the range
16-22 ml $/ \mathrm{kg}$ (mean $20.4 \mathrm{ml} / \mathrm{kg}$ ). ${ }^{20}$ The values obtained for ventilated healthy children are up to $50 \%$ more than this. ${ }^{11}$.

\section{SUMMARY}

The mechanical characteristics of the ventilated lung can only be interpreted when the volume of the lung (FRC), the elastic properties $\left(\mathrm{C}_{\mathrm{dyn}}\right)$, and the degree of airway obstruction $\left(\mathrm{R}_{\mathrm{e}}\right)$ are accurately quantified with pulmonary function testing. More gentle ventilation strategies (permissive hypercapnia) are used and the efficacy of mechanical ventilation can be verified by $\mathrm{PTCCO}_{2}, \mathrm{PETCO}_{2}$, and the measurement of FRC, $\mathrm{C}_{\text {dyn }}$ and $\mathrm{R}_{\mathrm{e}}$ in the intensive care unit. Pulmonary function testing brings new insights, awareness, and applications, but its limitations need to be taken into account when interpreting the acquired data

\section{Authors' affiliations}

A Schibler, Neonatal and Paediatric Intensive Care Unit, Department of Paediatrics, University of Bern, Bern, Switzerland

U Frey, Paediatric Respiratory Medicine, Department of Paediatrics, University of Bern

\section{REFERENCES}

1 Pfenninger J, Aebi C, Bachmann D, et al. Lung mechanics and gas exchange in ventilated preterm infants during treatment of hyaline membrane disease with multiple doses of artificial Surfactant (Exosurf). Pediatr Pulmonol 1992:14:10-15.

2 Goldsmith LS, Greenspan JS, Rubenstein D, et al. Immediate improvement in lung volume after exogenous surfactant: alveolar recruitment versus increased distention. J Pediatr 1991;119:424-8.

3 Freezer NJ, Sly PD. Predictive value of measurements of respiratory mechanics in preterm infants with HMD. Pediatr Pulmonol 1993; 16:1 16-23.

4 Tepper RS, Rosenberg D, Eigen $\mathrm{H}$, et al. Bronchodilator responsiveness in infants with bronchiolitis. Pediatr Pulmonol 1994;122:145-51.

5 Sly PD, Lanteri CJ, Nicolai T. Measurement of respiratory function in the intensive care unit. In: Stocks J, ed. Infant respiratory function testing. New York: Wiley-Liss Inc, 1996:445-84.

6 Arnold JH, Stenz RI, Thompson JE, et al. Noninvasive determination of cardiac output using single breath $\mathrm{CO}_{2}$ analysis. Crit Care Med 1996;24:1701-5.

7 Sivan $\mathrm{Y}$, Eladah MK, Cheah T, et al. Estimation of arterial carbon dioxide by end-tidal and transcutaneous $\mathrm{P}_{\mathrm{CO} 2}$ Measurements in ventilated children. Pediatr Pulmonol 1992;12:153-7.

8 Ream RS, Schreiner MS, Neff JD, et al. Volumetric capnography in children. Anesthesiology 1995;82:64-73.

9 Mariani G, Cifuents J, Waldemar AC. Randomized trial of permissive hypercapnia in preterm infants. Pediatrics 1999;104:1082-8.

10 Lanteri CJ, Kano S, Nicolai T, et al. Measurement of dynamic respiratory mechanics in neonatal and paediatric intensive care: the multiple linear regression technique. Pediatr Pulmonol 1995;19:29-45.

11 Sivan Y, Deakers TW, Newth CJL. Functional residual capacity in ventilated infants and children. Pediatr Res 1990;28:451-4.

12 Schule A, Schaller P, Topfer A, et al. Measurement of functional residua capacity by sulfur hexafluoride in small-volume lungs during spontaneous breathing and mechanical ventilation. Pediatr Res 1994:35:494-9.

13 Schibler A, Henning R. Measurement of functional residual capacity in rabbits and children using an ultrasonic flow meter. Pediatr Res 2001;49:581-8.

14 Kraemer R, Meister B. Fast real-time moment-ration analysis of multiple breath nitrogen washout in children. J Appl Physiol 1985;59:1 137-44.

15 Schibler A, Schneider M, Frey U, et al. Moment ratio analysis of the multiple nitrogen washout in infants with lung disease. Eur Respir J 2000;15:1094-101.

16 Habib RH, Lutchen KR. Moment analysis of the multiple nitrogen washout based on alveolar gas dilution number. Am Rev Respir Dis 1991;144:513-19.

17 Vilstrup CT, Biörklund J, Larsson A, et al. Functional residual capacity and ventilation homogeneity in mechanically ventilated small neonates. $J$ Appl Physiol 1992;73:276-83.

18 Larsson A, Jonmarker C, Werner $\mathrm{O}$. Ventilation inhomogeneity during controlled ventilation. Which index should be used? J Appl Physiol 1988; 65:2030-9.

19 Sivan Y, Deakers TW, Newths CJL. An automated bedside method for measuring functional residual capacity by $\mathrm{N}_{2}$ washout in mechanically ventilated children. Pediatr Res 1990;28:446-50.

20 Tepper RS, Asell S. Comparison of helium dilution and nitrogen washout measurements of functional residual capacity in infants and very young children. Pediatr Pulmonol 1992;13:250-4. 